\title{
Suitability of techniques for analyzing particle size of rice husk ash (RHA) from sieve analysis data
}

\author{
ljabo, O. J. ${ }^{1}$ and I. O. Agbede ${ }^{2}$ \\ ${ }^{1}$ Department of Agricultural and Environmental Engineering, University of Agriculture, \\ Makurdi, Nigeria.ojijabo@yahoo.com \\ ${ }^{2}$ Department of Civil Engineering, University of Agriculture, Makurdi, Nigeria. \\ femiagbede2002@yahoo.com.
}

\begin{abstract}
Four different algorithms were used to evaluate the numerical values of particle size of unground RHA with a view to determining the most suitable algorithm. The experimental design used was a $5 \times 4$ two-factor in complete block randomized design (CBRD). Five RHA types form the five levels of one factor while the four algorithms form the block or the second factor at four levels. The particle size distribution of each sample was generated and used for the analysis by each of the four algorithms. The four algorithms used were Henderson and Perry's technique, British Standard fitted with quadratic equation, British Standard fitted with logarithmic function and ASABE Standard. The raw particle size data, the coefficients of variation of various replications and coefficient of determinations were each subjected to ANOVA and separation of means at $\alpha=$ 0.05. It was found that Henderson and Perry's technique clearly gave the highest values of particle size while British Standard fitted with quadratic curve was most suitable on account of low coefficient of variation of the replicate values and high coefficient of determination of the trendlines fitted. Henderson and Perry's technique is to be used with caution in situations where the other algorithms could not easily detect treatment effects.
\end{abstract}

Keywords: Ash, suitable algorithm, particle size, prediction, curve-fitting

\section{INTRODUCTION}

Rice husk ash (RHA) is the solid product of combustion of rice husk whose quality such as fineness, specific surface area and silica content depends on the burning method. RHA is available in all the 105 rice producing countries of the world (FAOSTAT, 2007). Table 1 shows the mean production of rice and the potential availability of rice husk and RHA for the top 20 world producers of rice averaged for a decade, 1996 to 2005 . The projection figures are indicative that RHA is available in abundance and would provide enough raw materials to sustain both existing and emerging industries.

RHA can be tailor-made to meet the requirements of various users. Apart from the two main uses as an insulator in the steel industry and as a pozzolana in the cement and building industry (Anon, 2003; Bui,
2001; Agbede and Obam, 2008), emerging uses include its use as an absorbent of both oil (Chou et al., 2001) and moisture (ljabo, 2010), in silicon chip manufacture (Kapur, 1985), to prevent insect attack in stored food stuff, for water purification, as a soil ameliorant to help break up clay soils and improve soil structure (Anon, 2003). Some of these uses require the knowledge of the particle size of the RHA. For example, Bui (2001) had to grind RHA to enhance strength of the mortar because the fineness of the ash strongly influences the strength of the specimen, and in the study determined particle sizes with varying grinding times. In an attempt to reduce the particle size of RHA to microscopic range some investigators resorted to pretreatment of the husk either by leaching with dilute acid (Chakraverty et al., 1988) or refluxing with concentrated acid (Jitcharoen et al., 2009). 
Am. J. Sci. Ind. Res., 2011, 2(4): 652-659

Table 1: Mean Production of Rice and Potential Availability of Two of Its Residues, in Thousands of Metric Tonnes, for The Top 20 World Producers of Rice Averaged for A Decade, 1996 To 2005

\begin{tabular}{llllll}
\hline S/No & Country & Rice & \%World & Husk & Ash \\
\hline & World & 591589 & 100.00 & 130150 & 32537 \\
2 & China & 187111 & 31.63 & 41164 & 10291 \\
3 & India & 128143 & 21.66 & 28191 & 7047 \\
4 & Indonesia & 51464 & 8.70 & 11322 & 2830 \\
5 & Bangladesh & 34636 & 5.85 & 7619 & 1905 \\
6 & Viet Nam & 32005 & 5.41 & 7041 & 1760 \\
7 & Mhailand & 25979 & 4.39 & 5715 & 1429 \\
8 & Myanmar & 20981 & 3.55 & 4616 & 1154 \\
9 & Japilippines & 12411 & 2.10 & 2730 & 683 \\
10 & Brazil & 11442 & 1.93 & 2517 & 629 \\
11 & US of America & 10496 & 1.77 & 2309. & 578 \\
12 & Pakistan & 9152 & 1.55 & 2013 & 503 \\
13 & Korea, Republic & 7058 & 1.19 & 1553 & 388 \\
14 & Egypt & 1.17 & 1516 & 379 \\
15 & Cambodia & 5893 & 0.96 & 1246 & 312 \\
16 & Nepal & 4118 & 0.96 & 906 & 227 \\
17 & Nigeria & 4035 & 0.68 & 888 & 222 \\
18 & Islamic Rep of Iran & 3,542 & 0.60 & 779 & 195 \\
19 & Sri Lanka & 3,126 & 0.59 & 770 & 192 \\
20 & Madagascar & 3,030 & 0.51 & 688 & 172 \\
\hline & & & 667 & 167 \\
\hline
\end{tabular}

Source: FAOSTAT, 2007

On the other hand, a common trend is to use the ash in its existing form as it is produced, which means particle size could be in the microscopic or sieve range. Sieve analysis could be a cheaper and a more common method of determining the particle size of many non-sticky particulate materials (ASABE, 2009) than other techniques like laser particle size analyzer. It is along this later opinion that this study derives its two-point objectives of determining the suitability of sieve analysis in evaluating particle size of five types of unground RHA and also to establish which algorithm is most suitable for analyzing the data generated by sieve analysis.

The suitability of sieve analysis for evaluating particle size of particulate materials in this study is based on the premise set by ASAE S319.3 JUL99 (ASABE, 2009) which says, "When a charge of sample (RHA) is subjected to sieve analysis, if 20 percent or more of the material, by weight, passes through the smallest sieve, then the fine materials, i.e. the sample concerned should be subjected to a non-sieving particle size analysis." On the other hand, when less than 20 percent of a charge, by weight, passed through the smallest sieve, the weight of the ashes on each sieve is taken and used for the analysis. Based on the weight distribution recorded, four different algorithms were used to calculate the particle size in $\mathrm{mm}$ for a batch. 


\section{MATERIALS AND METHODS}

MATERIALS: Five types of RHAs were obtained as follows:

1. Boiler furnace of a rice processing factory, OLAM Nigeria PLC, situated along University of Agriculture Road, Makurdi in Benue State of Nigeria. This was designated LAM.

2. An open heap of fresh ash (husk still burning in some parts and never beaten by rain) from Aliade rice mills in Benue State, Nigeria. This was designated ALD.

3. An open heap of fresh ash from Gboko rice mills in Benue state, Nigeria and was designated GBK.

4. Ash obtained by firing dried pre-boiled husks from OLAM in a laboratory furnace set at $600{ }^{\circ} \mathrm{C}$ for three hours according to Hanfi et al.'s (1980) method. This was designated HAN.

5. Ash generated in accordance to Jitcharoen et al.'s (2009) recommendation for a high specific surface area ash. The method prescribes reflux boiling of the clean husk in $5 \mathrm{M} \mathrm{HCl}$ for three hours then dried prior to firing in a laboratory furnace at $600{ }^{\circ} \mathrm{C}$ for another 3 hours. This was designated JPC.

Experimental design: A $5 \times 4$ two-factor experiment in complete randomized block design (CRBD) was used to test for significant difference of means of the particle size of each of the five types of ashes. Ash type at the five levels of ALD, GBK, HAN, JPC and LAM form the treatment while the algorithms for obtaining particle size value from size distribution at four levels form the block. The four levels for the algorithms were Henderson and Perry's (1976) algorithm, British Standard (2003) fitted with logarithmic curve, British Standard (2003) fitted with quadratic curve and ASABE Standards (2009). The experiment had three replications.

Table 2 was used to obtain particle size by Henderson and Perry's algorithm. For the other algorithms which include graphical methods the particle size distribution data from sieve analysis were first transformed to cumulative percent less than the sieve size indicated as in Table 3, from which the typical format that these algorithms were used, as shown in Figures 1, 2 and 3

\section{RESULTS AND DISCUSSION}

Suitability of Sieve Analysis for Determination of Particle Size of RHA: Table 2 is a typical data from which Table 3 is derived. From Table 3 the cumulative mass, percent less than sieve size $75 \mu \mathrm{m}$ is zero for the three replications of GBK ash. For the other four types of RHA, the cumulative mass is also zero or less than one percent for each of the replications. That is, the percent mass of RHA that passed through sieve with opening $75 \mu \mathrm{m}$ is nearly zero for all cases. In a standard sieve analysis,

sieve with $53 \mu \mathrm{m}$ opening is regarded as the smallest sieve. The smallest available size in this study is 75 $\mu \mathrm{m}$ which is even larger than $53 \mu \mathrm{m}$, yet less than one percent of the mass of the RHA passed through it. When the less-than-one percent situation in this study is compared with the more-than-20\% recommended by ASABE (2009) it can be said that sieve analysis is suitable for particle size determination of unground RHA.

Optimum Algorithm for Obtaining Particle Size from Sieve Analysis Data: All the four different algorithms used for analyzing sieve data to obtain particle size of the five types of rice husk ash as shown in Figure 4 all agree that RHA obtained from OLAM boiler furnace has the highest particle size. Similarly, three of the algorithms are in harmony that JPC ash has the least value. Only ASABE (2009) graphical technique indicated a different ash type than that from JPC's method, which is HAN's method, as having the least particle size of 0.2066 $\mathrm{mm}$. In terms of individual algorithms, Henderson and Perry's (1976) algorithm gave the highest values in the range $0.5901 \mathrm{~mm}$ for JPC RHA to $3.0875 \mathrm{~mm}$ for RHA from OLAM furnace. This was followed by particle size range as calculated by British Standard (2003) fitted with logarithmic function with values ranging from $0.2166 \mathrm{~mm}$ of ash by JPC's method to $0.3733 \mathrm{~mm}$ for OLAM ash then the British Standard (2003) fitted with quadratic function followed with the range of $0.2 \mathrm{~mm}$ to $0.3433 \mathrm{~mm}$. ASABE (2009) standard had the least lower limit and values in the range of $0.2066 \mathrm{~mm}$ to $0.3766 \mathrm{~mm}$.

Table 4 which gives ANOVA for two-factor with replication for particle size of 5 types of RHA by 4 different algorithms of analyzing sieve data has a calculated F-value greater than F-critical for each of the algorithms and type of RHA. Therefore, it can be said that both the algorithm and type of RHA have significant effect on particle size of ungrounded RHA at $\alpha=0.05$ level. 
Am. J. Sci. Ind. Res., 2011, 2(4): 652-659

Table 2: Algorithm for Using Henderson and Perry's Method for Calculating Particle Size of Five Types of RHA

\begin{tabular}{|c|c|c|c|c|c|c|c|c|c|c|c|}
\hline \multirow{3}{*}{$\begin{array}{l}\text { Sieve } \\
\text { size, } \mu \mathrm{m}\end{array}$} & \multicolumn{5}{|c|}{ Ash type } & \multicolumn{6}{|c|}{ Ash type } \\
\hline & ALD & GBK & HAN & JPC & LAM & \multirow[b]{2}{*}{ RANK } & ALD & GBK & HAN & JPC & LAM \\
\hline & \multicolumn{5}{|c|}{ Percent ash retained on the indicated sieve size } & & \multicolumn{5}{|c|}{ Rank x \% wt fraction retained on the indicated sieve } \\
\hline 850 & 0.48 & 1.95 & 0.92 & 2.86 & 11.32 & 11.33333 & 5.4230 & 22.1136 & 10.4459 & 32.3805 & 128.3024 \\
\hline 600 & 1.91 & 5.37 & 2.30 & 2.86 & 14.15 & 8.00 & 15.3112 & 42.9272 & 18.4328 & 22.8568 & 113.2072 \\
\hline 425 & 4.31 & 7.32 & 3.23 & 14.29 & 12.26 & 5.67 & 24.4018 & 41.4636 & 18.2795 & 80.9523 & 69.4971 \\
\hline 300 & 29.67 & 22.93 & 19.82 & 2.86 & 26.42 & 4.00 & 118.6604 & 91.7072 & 79.2628 & 11.4284 & 105.6604 \\
\hline 150 & 50.72 & 44.88 & 68.66 & 25.71 & 25.00 & 2.00 & 101.4354 & 89.7560 & 137.3272 & 51.4286 & 50.0000 \\
\hline 75 & 12.92 & 17.56 & 5.07 & 51.43 & 10.85 & 1.00 & 12.9187 & 17.5610 & 5.0691 & 51.4286 & 10.8491 \\
\hline TOTAL & 100.00 & 100.00 & 100.00 & 100.00 & 100.00 & & 278.1505 & 305.5286 & 268.8174 & 250.4752 & 477.5162 \\
\hline \multicolumn{3}{|c|}{ Fineness Modulus } & & & & & 2.7815 & 3.0553 & 2.6882 & 2.5048 & 4.7752 \\
\hline \multicolumn{3}{|c|}{ Particle size in $\mathrm{mm}$} & & & & & 0.7160 & 0.8657 & 0.6712 & 0.5910 & 2.8516 \\
\hline
\end{tabular}

Table 3: Cumulative Mass, \% Less Than Sieve Size Indicated

\begin{tabular}{|c|c|c|c|c|c|c|}
\hline \multirow{3}{*}{$\begin{array}{l}\text { Replica- } \\
\text { tion }\end{array}$} & \multirow{3}{*}{$\begin{array}{c}\text { Sieve } \\
\text { size, } \mu \mathrm{m}\end{array}$} & \multicolumn{5}{|c|}{ Rice Husk Ash Type } \\
\hline & & ALD & GBK & HAN & JPC & LAM \\
\hline & & \multicolumn{5}{|c|}{ Cumulative mass, $\%$ less than sieve size indicated } \\
\hline & 850 & 99.5215 & 98.0488 & 99.0783 & 97.1429 & 88.6792 \\
\hline & 600 & 97.6076 & 92.6829 & 96.7742 & 94.2858 & 74.5283 \\
\hline \multirow[t]{6}{*}{1} & 425 & 93.3014 & 85.3658 & 93.5484 & 80.0001 & 62.2641 \\
\hline & 300 & 63.6363 & 62.439 & 73.7327 & 77.143 & 35.849 \\
\hline & 150 & 12.9186 & 17.561 & 5.0691 & 51.4287 & 10.849 \\
\hline & 75 & 1E-04 & 0 & $8 E-15$ & 1E-04 & 1E-04 \\
\hline & 850 & 99.5169 & 98.3333 & 99.3007 & 96.1538 & 88.5714 \\
\hline & 600 & 98.0676 & 92.0833 & 96.5035 & 92.3076 & 74.2857 \\
\hline \multirow[t]{6}{*}{2} & 425 & 94.686 & 87.9166 & 89.5105 & 88.4614 & 61.9047 \\
\hline & 300 & 61.3527 & 60.4166 & 71.3287 & 84.6152 & 39.9999 \\
\hline & 150 & 11.1112 & 14.9999 & 8.3916 & 30.769 & 12.857 \\
\hline & 75 & 0.0001 & 0 & 0.6993 & 0 & 0.476 \\
\hline & 850 & 99.5169 & 95.6731 & 99.3939 & 96.6484 & 82.4074 \\
\hline & 600 & 96.6183 & 91.3462 & 98.7878 & 93.2968 & 73.1481 \\
\hline \multirow[t]{4}{*}{3} & 425 & 91.7874 & 84.1347 & 98.1817 & 84.2309 & 55.0925 \\
\hline & 300 & 53.6231 & 40.8655 & 91.515 & 80.8793 & 33.7962 \\
\hline & 150 & 4.8308 & 9.6155 & 23.0302 & 41.0991 & 11.574 \\
\hline & 75 & 0 & 0 & 0 & 0 & 0.4629 \\
\hline
\end{tabular}


Am. J. Sci. Ind. Res., 2011, 2(4): 652-659
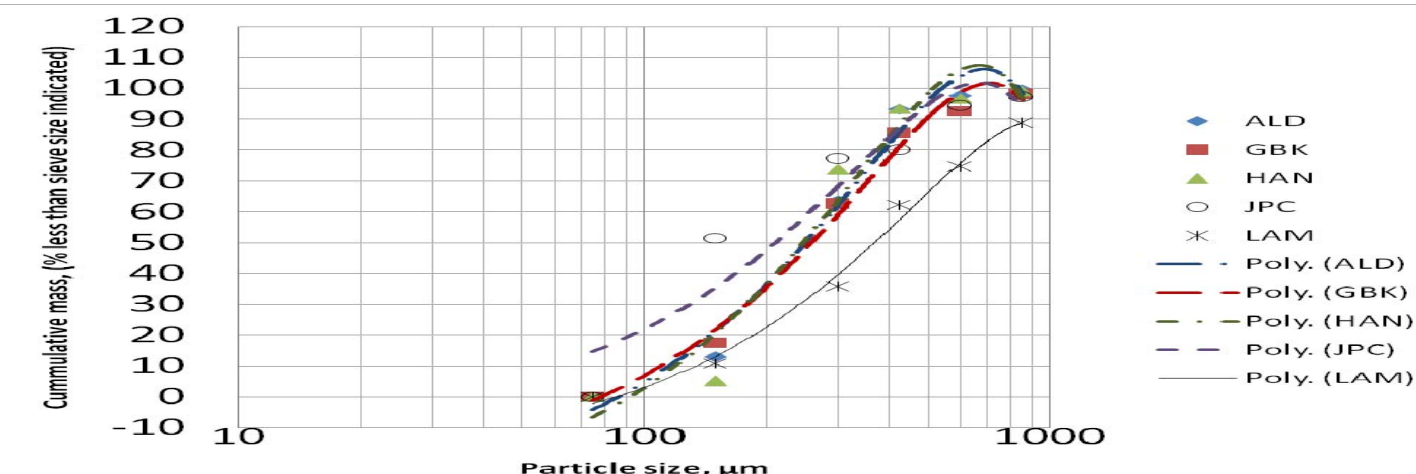

Particle size, $\mathrm{mm}$

Fig 1: Quadratic Fitting to Measured Particle Size of Five Types of RHA Using British Standard

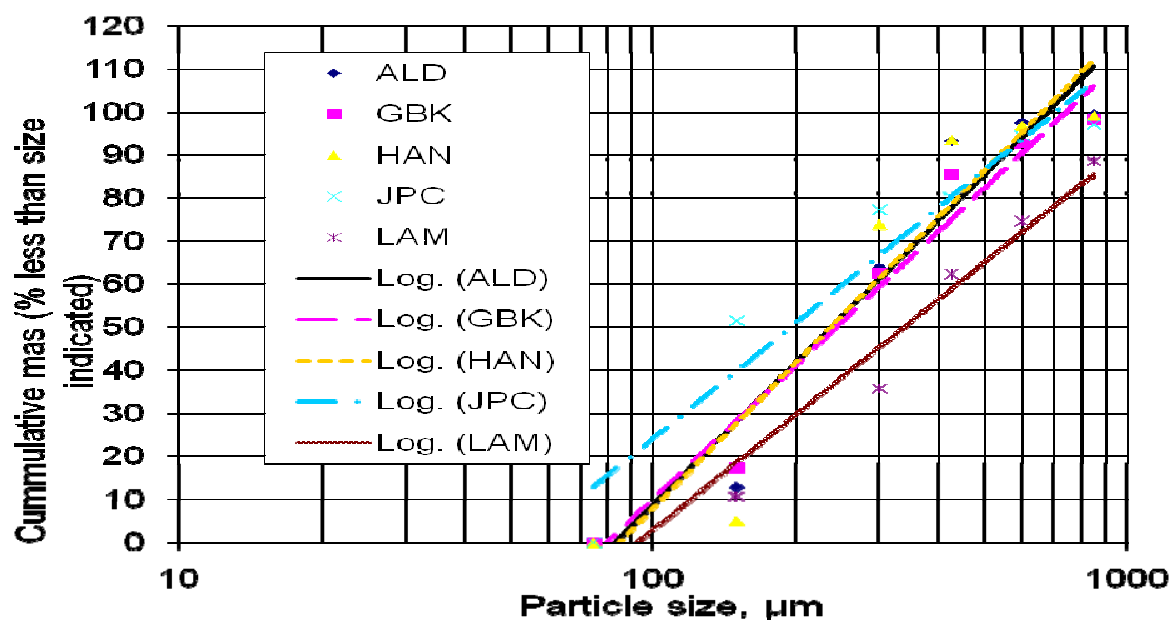

Fig 2: Particle size distribution of five types of RHA using British standard fitted with logarithmic function

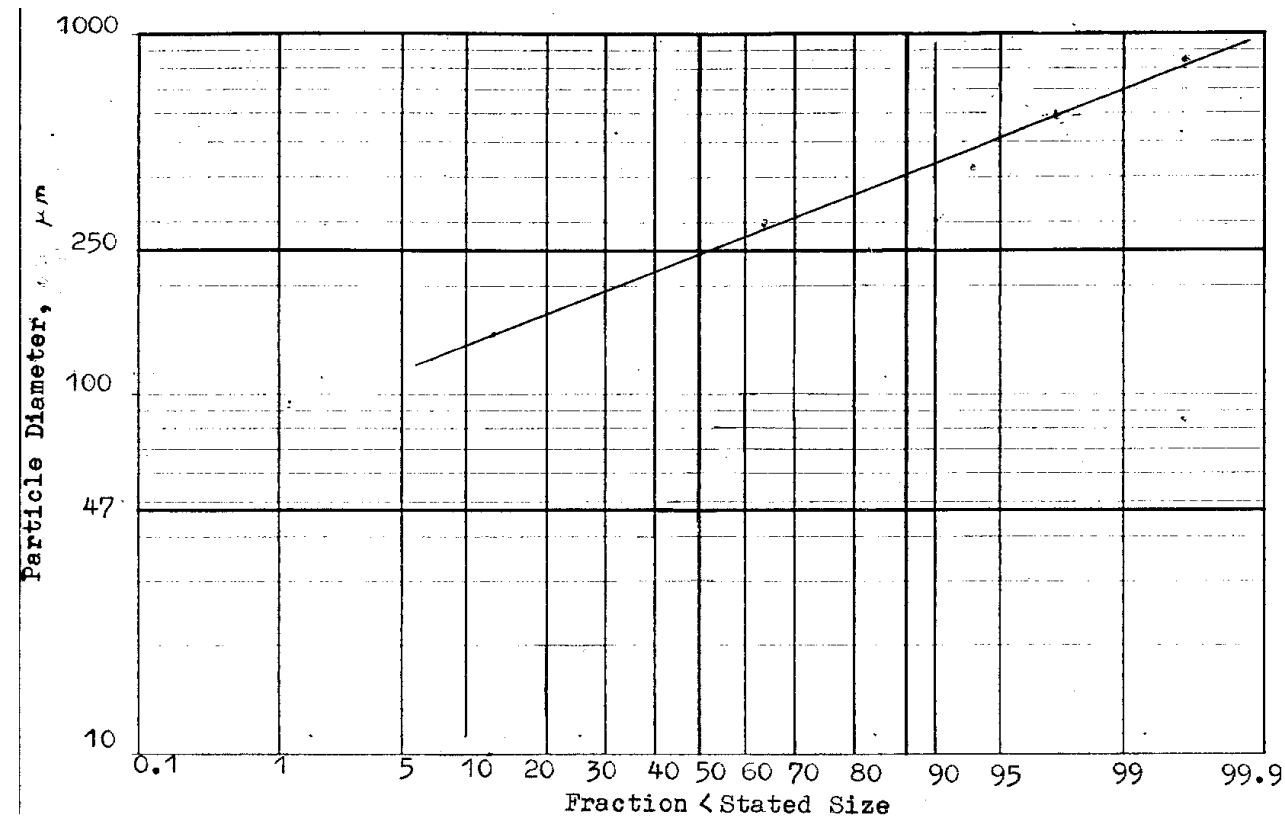

Fig 3 ASABE Graphical Method of Determining Particle Size of Rice Husk Ash 
Separation of means was done using a t-Test with two-sample assuming unequal variances at $\alpha=0.05$ according to Microsoft Excel $\circledast$ (2007). Thus it can be seen that irrespective of the technique of analyzing the sieve data, the particle size of fresh ash fetched from Aliade rice mill is not significantly different from that from Gboko. In addition Henderson and Perry's (1976) method and British Standard fitted with quadratic equations indicated that the particle size of three ash types, i.e. fresh ash fetched from Aliade and Gboko rice mills as well as ashes generated by HAN's method are not significantly different from each other. This is graphically displayed in Figure 4. The two criteria of over-lapping of range of values as can be seen in Figure 4 and low coefficient of variation for the replicate values of particle size as reflected in Table 5 were set as indices for determining the suitable algorithm for obtaining particle size of unground RHA from sieve data. Applying the first criterion, Henderson and Perry's (1976) algorithm, which one would expect to be more accurate and precise as it is entirely by calculation, has a higher range of values outside the range of all the other three graphical, more approximate methods. When all the three other graphical techniques are lumped together, they produce particle size in the range of $0.2066 \mathrm{~mm}$ to $0.3766 \mathrm{~mm}$ which is confirmed by t-test for separation of means to be statistically significantly lower than $0.5901 \mathrm{~mm}$ to $3.0875 \mathrm{~mm}$ from Henderson and Perry's technique involving fineness modulus. This no-over-lap of range condition obtained by Henderson and Perry's method compared with the other three is suggestive that Henderson and Perry's method predicts higher particle size of existing RHA that are not pulverized by grinding in a mill.

The criterion of coefficient of variation was applied by getting the coefficient of variation of the triplicate samples of each ash type and finding the mean for each technique regarding each ash type only as a replicate of the technique as shown in the last column of Table 5. The ANOVA of Table 5 as shown in Table 6 gives $F$ values greater than Fcrit indicating that at least one of the techniques is/are statistically significantly different from each other. Furthermore ttest was used to separate the means and as

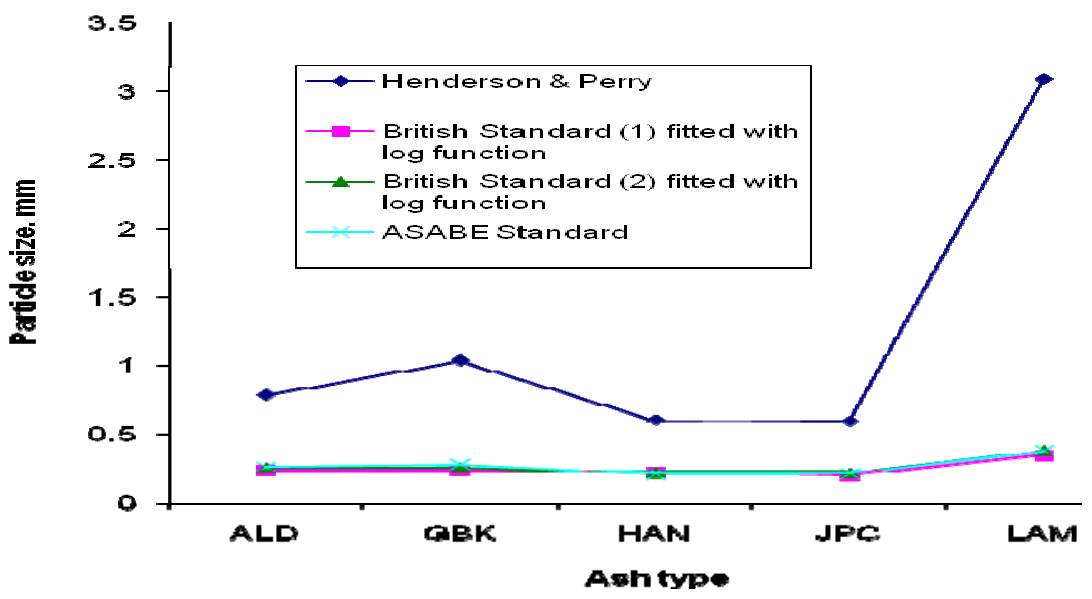

Fig. 4: A plot of particle sizes of five RHA types by four different algorithms

Table 4: A Two-Factor ANOVAs with Replication of Particle Size of 5 Types of RHA by four techniques of Analyzing Sieve Data

\begin{tabular}{|l|r|r|r|r|r|r|}
\hline \multicolumn{1}{|c|}{ Source of Variation } & \multicolumn{1}{c|}{ SS } & \multicolumn{1}{c|}{$\boldsymbol{d f}$} & \multicolumn{1}{c|}{$\boldsymbol{M S}$} & \multicolumn{1}{c|}{$\boldsymbol{F}$-value } & \multicolumn{1}{c|}{$\boldsymbol{F ~ c r i t}$} \\
\hline Technique of analysis & 10.38543 & 3 & 3.46181 & 157.6687 & $3.41 \mathrm{E}-22$ & 2.838746 \\
\hline Ash Type & 4.656803 & 4 & 1.164201 & 53.02369 & $1.82 \mathrm{E}-15$ & 2.605972 \\
\hline Interaction & 8.974108 & 12 & 0.747842 & 34.06059 & $3.42 \mathrm{E}-17$ & 2.003461 \\
\hline Within & 0.878249 & 40 & 0.021956 & & & \\
\hline & & & & & & \\
\hline Total & 24.89459 & 59 & & & & \\
\hline
\end{tabular}


shown in Table 5 coefficient of variation of Henderson and Perry's method of 16.83 percent is significantly higher than the other three and above the acceptable upper limit of 15 percent generally accepted for methods and instruments.

Although Henderson and Perry's method is simple, it has two relative disadvantages. One, it tends to over- predict particle size of RHA and two; it gave a coefficient of variation far above others and the recommended upper limit value. For these two cogent reasons, Henderson and Perry's method can only be used with caution while the other three techniques examined in this study can be applied more liberally.

Table 5: Coefficient of Variation of Particle Size of Five Types of RHA By Different Techniques.

\begin{tabular}{|c|c|c|c|c|c|c|}
\hline \multirow[b]{3}{*}{ Technique } & \multicolumn{5}{|c|}{ Ash Type } & \multirow[b]{2}{*}{ Mean* } \\
\hline & ALD & GBK & HAN & JPC & LAM & \\
\hline & \multicolumn{6}{|c|}{ Coefficient of variation, percent } \\
\hline Henderson and Perry's (1976) & 13.04 & 26.65 & 25.87 & 0.17 & 18.43 & $16.83 a$ \\
\hline $\begin{array}{l}\text { British Standard (2003) fitted with } \\
\text { quadratic function }\end{array}$ & 2.47 & 4.95 & 7.87 & 5.00 & 4.45 & $4.95 \mathrm{~b}$ \\
\hline $\begin{array}{l}\text { British Standard (2003) fitted with } \\
\text { logarithmic function }\end{array}$ & 4.00 & 9.93 & 9.09 & 2.66 & 4.09 & $5.96 \mathrm{~b}$ \\
\hline ASABE Standards (2009) & 4.00 & 9.93 & 9.09 & 2.66 & 4.09 & $5.96 \mathrm{~b}$ \\
\hline
\end{tabular}

${ }^{*}$ Means having the same letter in the same column are not statistically significantly different from each other at $\alpha=0.05$ according to t-Test: Two-Sample Assuming Unequal Variances of Microsoft Excel囚 (2003)

Table 6: A Two-Factor ANOVA Without Replication of Coefficient of Variation of 5 RHA Types And Four Algorithms.

\begin{tabular}{|l|r|r|r|r|r|r|}
\hline \multicolumn{1}{|c|}{$\begin{array}{c}\text { Source of } \\
\text { Variation }\end{array}$} & SS & $d f$ & MS & F & P-value & F crit \\
\hline Algorithm & 474.8941 & 3 & 158.298 & 7.570705 & 0.004197 & 3.490295 \\
\hline Ash type & 324.2238 & 4 & 81.05594 & 3.876552 & 0.030215 & 3.259167 \\
\hline Error & 250.9114 & 12 & 20.90929 & & & \\
\hline & & & & & & \\
\hline Total & 1050.029 & 19 & & & & \\
\hline
\end{tabular}

From the data in the last column of Table 5, the other three algorithms are not statistically significantly different from each other at $\alpha=0.05$ level. However, a deeper observation of the three algorithms could be revealing. ASABE standard graphical technique involved using a logarithmic - probability graph sheet to fit a straight line into the measured cumulative mass, percent less than sieve size indicated. To the best of the investigator's knowledge, probability scale is not available in most spreadsheets used for graphical analysis. This means that the use of ASABE standard graphical method would involve more approximate subjective steps than the others. So the ASABE standard graphical method can be dropped in favour of the British standards with either of the logarithmic or the quadratic fittings.

Next, the two fittings to observed data using the British standard were examined. First, the two fittings when examined in terms of coefficient of variation as in the last column of Table 5 the quadratic fitting has a preferably lower value of 4.95 percent compared to log fitting of 5.96 percent. Secondly, the mean correlation ratio or coefficient of determination, $R^{2}$, value of the fitted curves before their respective $d_{50}$ values were read out against particle size axis as the geometric mean particle size of the ash as shown in Table 6 were compared. The fittings have $R^{2}$ values which are not statistically significant from each other. However, like in the case of coefficient of variation, overall mean $R^{2}$ for quadratic curves fitted is higher than that of logarithmic fitting. Therefore, using any of the two coefficients, particle size values from quadratic fittings can be regarded as superior to those of logarithmic fittings within limits of the experimental errors in this study.

\section{CONCLUSION}

Sieve analysis data is suitable for determination of particle size of unground RHA. Out of the four algorithms used for determining particle size, the British standard fitted with logarithmic function, the 
British standard fitted with quadratic function and ASABE graphical algorithms are not significantly different from each other while Henderson and Perry's algorithm gives higher particle size values. However, on account of low coefficient of variation and high $\mathrm{R}^{2}$, British standard fitted with quadratic function is preferred to others.

\section{REFERENCES}

Agbede, I. O. and S. O. Obam. (2008). Compressive strength of rice husk ash-cement sandcrete blocks. Global Journal of Engineering Research 7(1);. No. 1, 43-46.

American Society of Agricultural and Biological Engineers (ASABE) 2009. ASABE Standards, ANSI/ASAE S319.3 FEB03. Method of determining and expressing fineness of feed materials by sieving. St Joseph MI 49085-9659.

Anon 2003. Rice Husk Ash Market Study. Technical Report of the DTI Renewable Energy Programme. ETSU U/00061/REP DTI/Pub URN 03/668 http://www.consumer.gov.uk/renewables/publications/e xp129.pdf Accessed 29 May 2008

British Standard Institution (BSI). (2003). Part 1. Specifications for precast concrete block. BS 2028, 1364. Gayland and Sons, London.

Bui, D.D. (2001). Rice husk ash as a mineral admixture for high performance concrete. Doctoral Thesis. ter nerkrijging van de graad van doctor aan de Technische Universytet Delft. pp 122

Chakraverty, A.; P. Mishra and H.D. Banerjee (1988). Investigation of combustion of raw and acid-leached rice husk for production of pure amporphous white silica. Journal of Materials Science 23(1) , 21-24.

Chou, K.; Tsai, I and C. Lo. (2001). The absorption of Congo red and vaccum pump oil by rice hull ash. Bioresource technology 78(2) 217 -219.

FAOSTAT Database. 2007. Major food and agricultural commodities and producers - commodities by country. http://www.fao.org/es/eso/top/commodity.html of January 23, 2008.

Hanfi, S., Abo- El-Enein, S. A., Ibrahim, D. M. and S. A. ElHemaly. (1980). Surface properties of silicas produced by thermal treatment of rice husk ash. Thermochemica Acta, $37 ; 137-143$

Henderson, S. M. and R. L Perry. (1976). Agricultural process engineering. 3ed. Westport Conn. Avi Publishing Co. pp 442.

ljabo, O. J. (2010). Studies in desiccant properties of rice husk ash (RHA). Doctoral Thesis in Processing and Storage Engineering, Department of Agricultural and Environmental Engineering, University of Agriculture, Makurdi.

Jitcharoen, J; A. Pimmongkon and P. Chantree. (2009). Production of Pure and High Specific Surface Area Silica from Black Glutinous Rice Husks with Hydrochloric Acid Pre-treatment. http://www.scicoc.or.th/stt/32/sec_e/paper/stt32_E_E0 110.p of October 192009

Kapur, P. C. (1985). Production of reactive bio-silica from the combustion of rice husk in a tube-in-basket (TiB) burner. Powder Technology 44(1):63-67

Microsoft $\AA$ Excel $₫$ 2007. Microsoft Corporation, USA. 